\title{
Autoradiographische Studien über die RNS-Synthese in den Verdauungsorganen der Mäuse mit Besonderer Berücksichtigung auf Zweikernige Zellen*
}

\author{
Shoji Omochi, Tetsuji Nagata, Osamu Shibata und Tokio Nawa \\ （尾持昌次, 永田哲士, 柴田 治, 名和橙黄雄)
}

Eingegangen am 8. September 1966

Die autoradiographischen Untersuchungen über die DNS-Synthese mittels der Injektion des ${ }^{3} \mathrm{H}$-Thymidin haben ergeben, daß in den Drüsenzellen und den Epithelzellen im Vergleich mit den einkernigen Zellen die zweikernigen Zellen mehr Silberkörner enthalten (Омосні et al. 19533, Nagata 1962). Dabei zeigen uns diese Resultate die Tatsache, daß die Zellen mit zwei Kernen funktionell höher gesteigert sind als die mit einem Kerne, weil die Zunahme der Silberkörner über die Kerne die Funktionssteigerung der betreffenden Zellkerne bedeutet. Es ist klar, daß der Grad der RNS Synthese in den Zellen im geraden Verhältnis zum Grade der Funktion der betreffenden Zellen steht. Dementsprechend sollen die Funktionssteigerungen der Zellen auch von Seiten der Cytoplasma nachweisen können, also mittels der Untersuchungen mit der Injektion des ${ }^{3} \mathrm{H}$-Uridin in die Versuchstiere. Das vorliegende Werk behandelt dieses Problem.

\section{Material und Methodik}

22 ausgewachsenen, $15 \mathrm{~g}$ schweren normal ernährten männlichen Albinomäuse fütterten wir mit dem Stückchen sogenannter Fundamentaldiät, die kompkt geformt ist und alle nötige Nährstoffe sowie Vitamine enthält, für eine Woche. Im Anfang der nächsten Woche, als die Tiere sich daran gewöhnten, solches Stückchen zu fressen, injizierten wir um 9 Uhr vormittags $20 \mu \mathrm{Ci}$ per Körpergewicht $(\mathrm{g}){ }^{3} \mathrm{H}$-Uridin einmalig subkutan. 1 Stunde nach der Injektion, also um $10 \mathrm{Uhr}$ vormittags und 25 Stunden nach der Injektion am nächsten Tag, um $10 \mathrm{Uhr}$ vormittags, wurden die Tiere gefüttert mit den Diätstückchen und 30 Minuten später wurden alle Reste der Diäten weggelassen. 2 Stunden nach der Injektion (1 Stunde nach der Fütterung, um 11 Uhr vormittags), 4 Stunden ( 3 St.), 8 Stunden ( 7 St.), 24 Stunden (23 Stunden, um 9 Uhr vormittags am nächsten Tag) je 5 Tiere, und 28 Stunden nach der Injektion (3 Stunden nach der Fütterung am nächsten Tag, um 1 Uhr nachmittags) wurden 2 Tiere getötet. Stückchen von Leber, Pankreas, Magen Duodenum, Jejunum, Ileum, Colon wurden mit eigenem Verfahren (Омосні et al. 1952, 1955, 1956, 1958, NAGATA et al. 1961) behandelt und so gewonnene Strichpräparate der isolierten Zellen wurden mit Photoemulsion-membran (Fuji EF2E) gedeckt und im Dunkel 55 Tage lang exponiert. Nach Entwicklung und Fixierung der Photoemulsion wurden die Zellen mit Hämatoxylin und Eosin gefärbt und im Balsam eingeschlossen. Die Zählung der Silberkörner wurde für Organ (bei der Epithelzellen im Darmkanal

* Diese Arbeit ist der Erinnerung an Prof. Masaji SEKI gewidmet. 


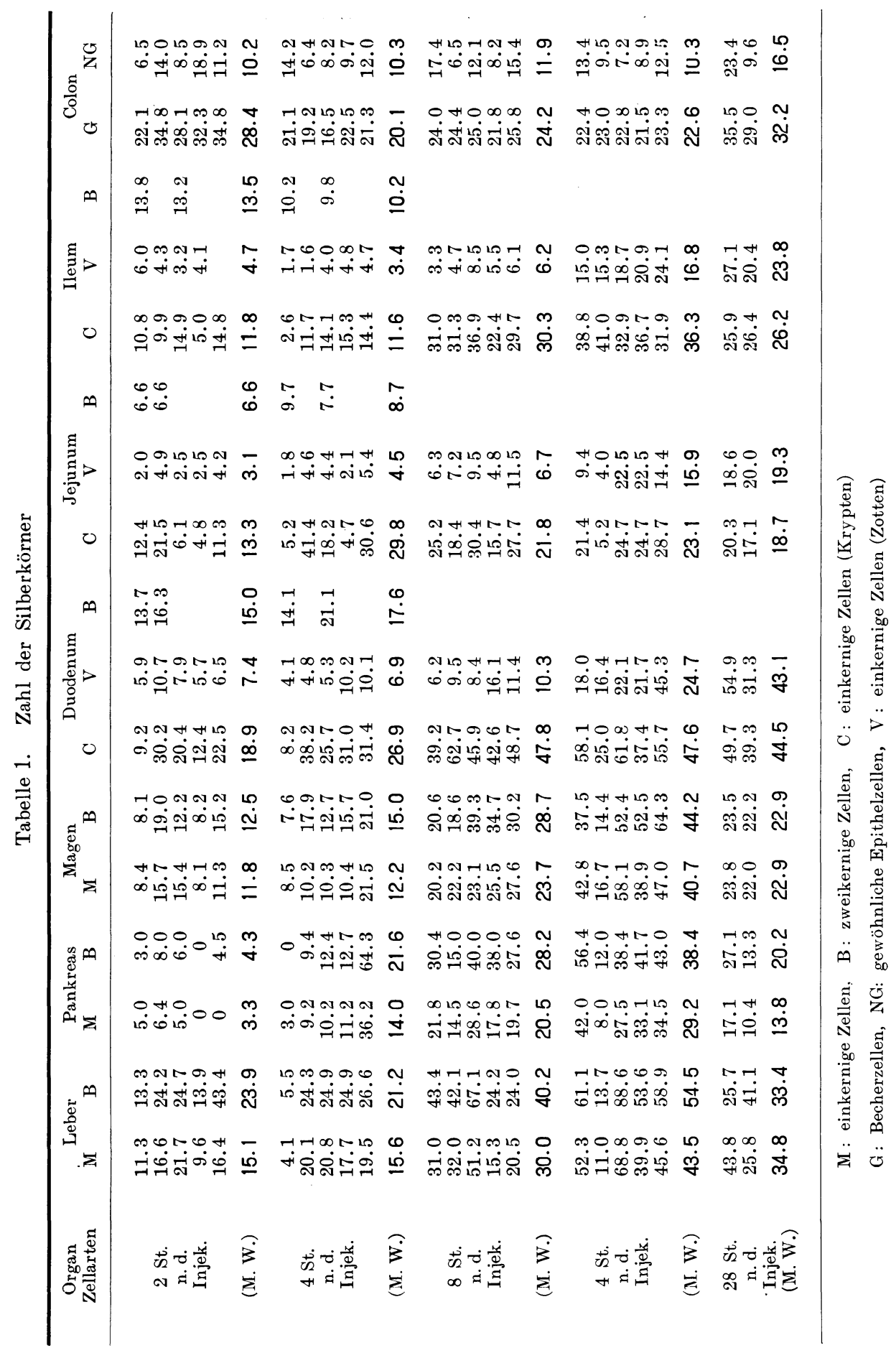


aber Zotten und Krypten für sich einzeln), für Tier und für ein- und zweikernige Zelle je 10 Zellen ausgeführt.

\section{Ergebnisse und Erörterungen}

Man kann mit der Tabelle 1 das Gesamtresultat der Zählung der Silberkörner erkennen. Hier findet man, daß die Zahl der Körner über die zweilsernigen Zellen in den Drüsenorganen wie Leber, Pankreas und auch Magen (Belegzellen) größer als die über die einkernigen ist, trotz alledem ist der Wert individuell verschieden. Diese Neigung ist in den Epithelien der Darmzotten auch der Fall.

Im Folgenden wollen wir die Resultate unserer Beobachtungen organweise darstellen.

Leber: In der Leber, wenn man die Zahl der Silberkörner am Mittelwert von 5 Tieren betrachtet, so hat sie sich nach der Injektion allmählich vermehrt und 24 Stunden später nach der Injektion im Vergleich mit dem Wert, den man 2 Stunden nach der Injektion fand, den zwei bis dreifachen Wert gezeigt. 28 Stunden nach der Injektion, d. h. 3 Stunden nach der Refütterung, hat sich die Körnerzahl im Vergleich mit der Zahl, die man vor der Refütterung fand, zu etwa drei- bis vierfünftel Werte vermindert. Die Silberkörner haben wir über die zweikernigen Zellen beträchtilich mehr als über die einkernigen gefunden, (Abb. 2 links).

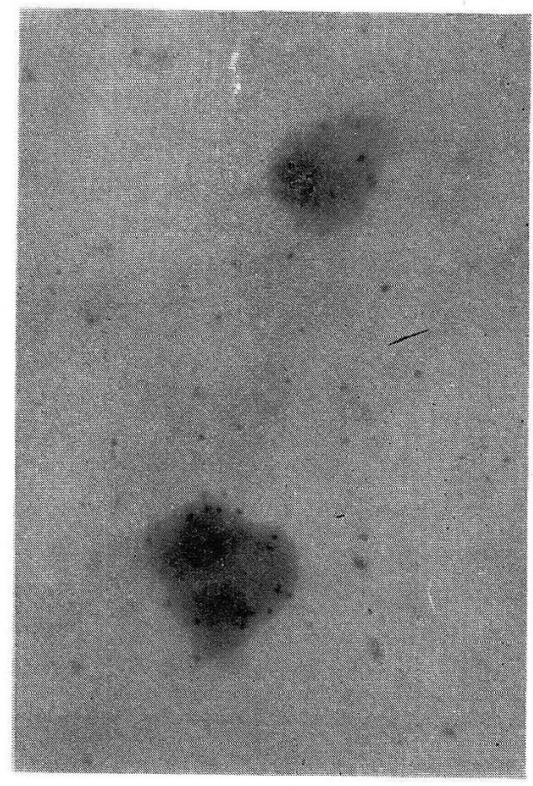

a

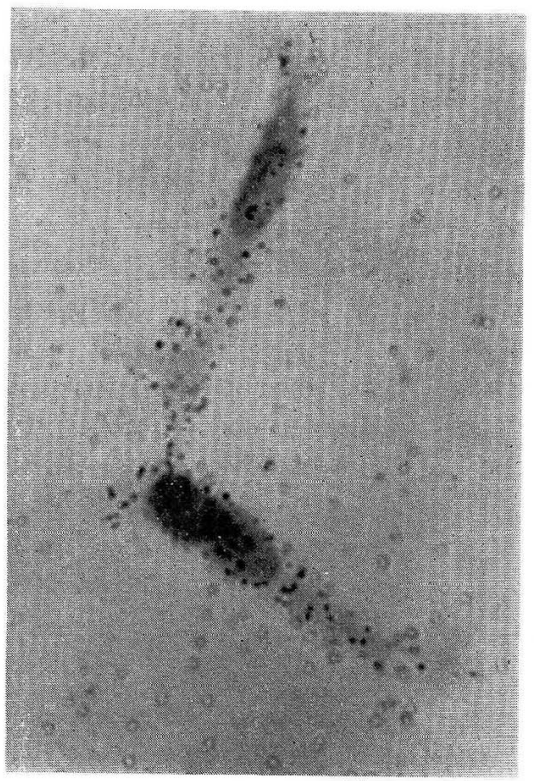

b

Abb. 1. Autoradiographie der isolierten Zellen. 4 Stunden nach der Injektion. Oben : einkernige Zellen, unten : zweikernige Zellen. a : exokrine Pankreaszellen $(\times 900)$,

b: Epithelzellen aus Zotten des Jejunums ( $\times 1300)$

Pankreas: Die Zahl der Silberkörner über die exokrinen Drüsenzellen der Bauchspeicheldrüse hat sich allmählich nach der Injektion vermehrt und 24 Stunden nach der Injektion hat sie, wie es in der Leber der Fall war, zum zwei bis dreifachen Wert erreicht, wenn auch der absolute Wert im Vergleich mit dem der Leber verhältnismäßig geringer war. 28 Stunden nach 


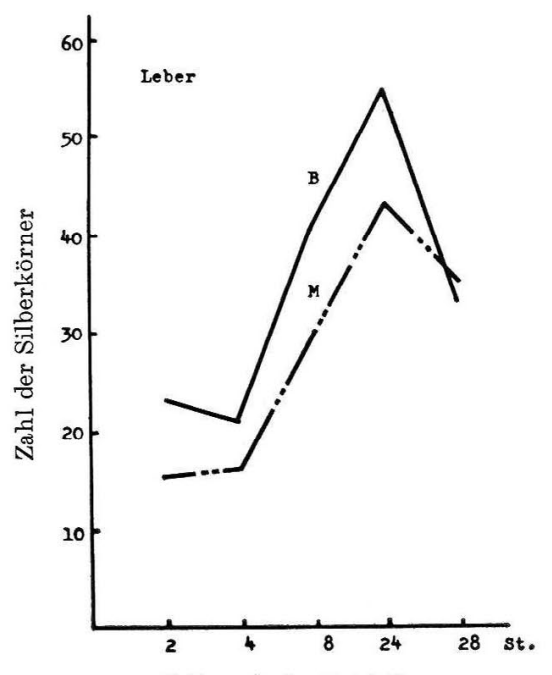

Zeit nach der Injektion

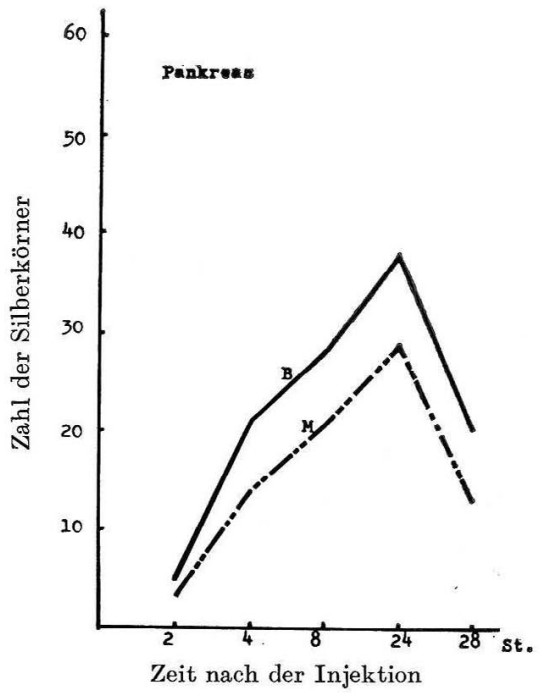

Zeit nach der Injektion

Abb. 2. Verhältnis der Zahl der Silberkörner mit der Zeit nach der Injekion. Links : Leber, rechts : Pankreas. Mittelwert von 5 Tieren. $M$ einkernige Zellen, $B$ zweikernige Zellen

der Injektion oder 3 Stunden nach der Refütterung hat sich die Zahl der Silberkörner auch beträchtlich vermindert (bis einhalb des maximalen Wertes). Die Zahl der Silberkörner über die zweikernigen Zellen war viel größer als die einkernigen (Abb. 1 a, 2 rechts).

Magen: In den Belegzellen des Magens auch die Ab- und Zunahme der Zahl der Silberkörner prinzipiell gleich wie die der Leber und der Bauchspeicheldrüse. Die Silberkörner haben wir über die zweikernigen Zellen zahlreicher als über die einkernigen gefunden, wenn auch die Differenz der Zahl der Silberkörner zwischen beiden Zellarten aber viel geringer war (Abb. 3 links).

Duodenum: Die Epithelien des Duodenums haben wir in zwei Arten klassifiziert, d. h. die aus Zotten stammende und die aus Krypten. In der Ersteren befindet sich einige zweikernige Zellen, aber in der Letzteren konnten wir solche kaum finden. Die Ersteren werden stärker markiert als die Letzteren. Die Zahl der Silberkörner über die Zellen aus den Krypten hat, ähnlich wie bei den Drüsenzellen, je nach den Stunden nach der Injektion ab- und zugenommen. Dagegen nahm die Zahl der Silberkörner über die einkernigen Zellen aus den Zotten allmählich nach der Injektion zu und nahm nicht ab. Die Silberkörner befinden sich auch über die zweikernigen Zellen größer als die einkernigen an der Zahl (Abb. 3 rechts).

Jejunum: Die Neigung, daß die Zahl der Silberkörner über die einkernigen Epithelzellen aus den Zotten nimmt nach der Injektion allmählich zu und daß die Zahl der Silberkörner über die Zellen aus den Krypten aber einige Stunden nach der Injekton zu ihrem höchsten Punkte erreicht und dann wieder sich vermindert, ist auch in Jejunum der Fall. Die Zahl der Silberkörner ist stets größer über die Zellen aus den Krypten (Abb. 4 links).

Ileum: Der Verlauf der Kurve ist der vorigen ähnlich, aber weit der des Duodenums ähneln. Hier aber müssen wir betonen, daß wenn auch die Zellen aus den Darmkrypten stärker als die der Zotten markiert werden, die Zahl der Silberkörner über die Zellen aus den Krypten nimmt 24 Stunden nach der Injektion ab, während die Zahl der Silberkörner über die Zellen aus den Zotten immer zunimmt (Abb. 4 rechts). 

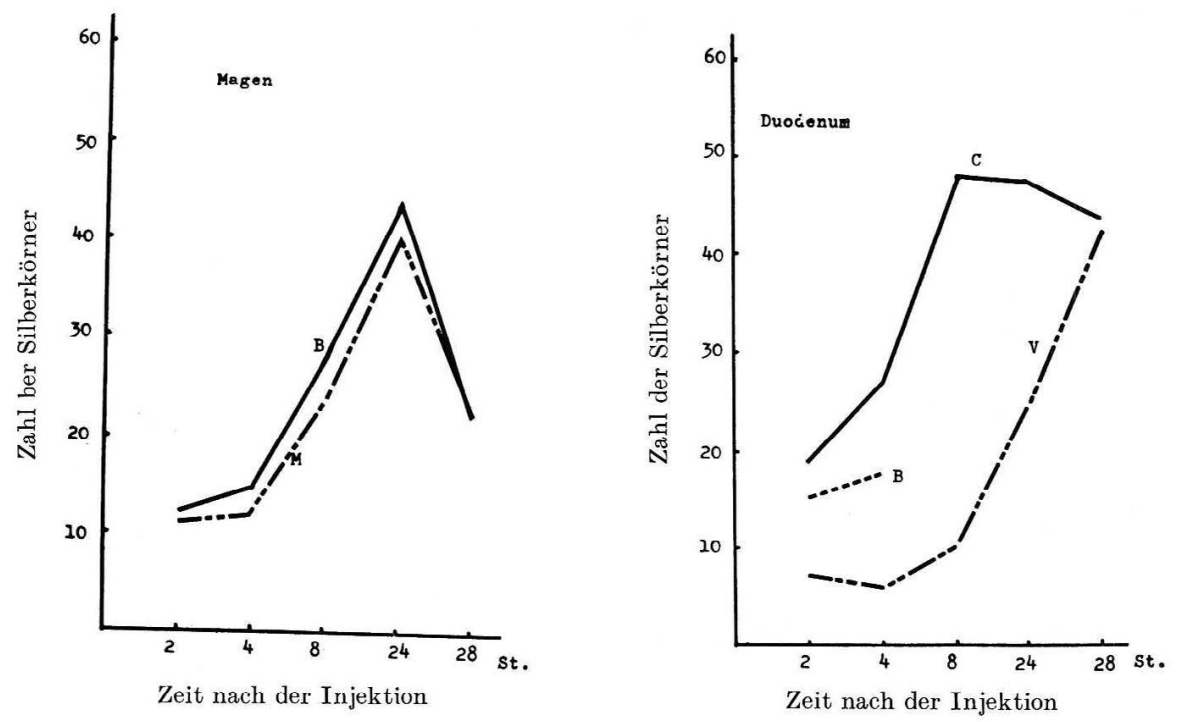

Abb. 3. Verhältnis der Zahl der Silberkörner mit der Zeit nach der Injektion. Links : Magen, rechts: Duodenum. Mittelwert von 5 Tieren. $M$ einkernige Zellen, $V$ dieselbe aus Zotten,

$C$ dieselbe aus Krypten, $B$ zweikernige Zellen (im Duodenum, die aus Zotten).
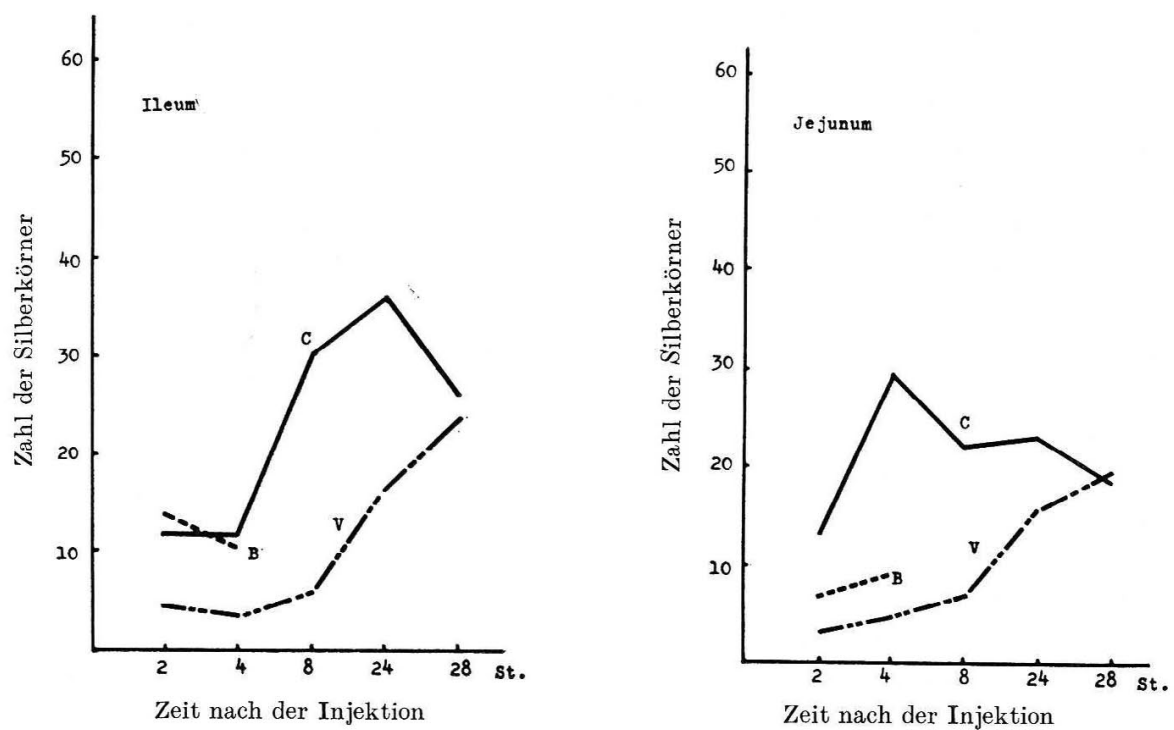

Abb. 4. Verhältnis der Zahl der Silberkörner mit der Zeit nach der Injektion. Links : Jejunum, rechts: Ileum. Mittelwert von 5 Tieren. $V$ einkernige Zellen aus Zotten, $C$ dieselbe aus Krypten, $B$ zweikernige Zellen aus Zotten.

Colon: Im Colon fehlen die Zotten und es gibt aber mehrere Becherzellen in den Krypten, so teilten wir die Zellen aus dem Colon in zwei Arten, d. h. in Becherzellen und in gewöhnliche Zylinderepithelzellen. Wie die Abb. 5 zeigt, enthalten die Becherzellen stets eine größere Zahl von Silberkörner über sich als die gewöhnliche Zylinderepithelzellen, zeigen aber 


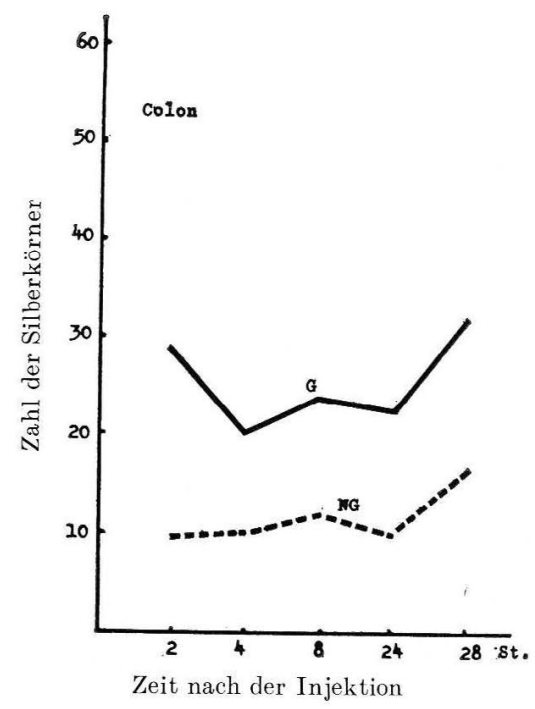

Abb 5. Verhältnis der Zahl der Silberkörner mit der Zeit nach der Injektion. Colon. Mittelwert von 5 Tieren. $G$ Becherzellen, $N G$ gewöhnliche Epithelzellen. keine merkwürdige zeitliche Schwankungen an der Zahl der Silberkörner.

Nach Schultze, Oehler und Maurer (1961), die den Umsatz der Ribonukleinsäure und des Eiweißes im Organismus von Maus und Ratte autoradiographisch untersucht hatten, ist die Markierungsweise der verschiedenen radioisotopen Substanzen wie ${ }^{3} \mathrm{H}$-Cytidin, ${ }^{3} \mathrm{H}$-Uridin, ${ }^{3} \mathrm{H}$-Leucin, ${ }^{3} \mathrm{H}-\mathrm{Ly}$ sin, ${ }^{3} \mathrm{H}-\mathrm{S}$-Aminosäuren fast gleich. Dabei hatten sie die verschiedenen Organe (Leber, Pankreas, Dünndarm, Speicheldrüse, Muskeln u. a.) untersucht, um den Einfluß der isotopen Substanzen bis 180 Minuten nach der Injektion zu verfolgen. Auch die andere Arbeit von Linnartz-Niklas, Hempel und Maurer (1961) behandelte den Einfluß auf dem Eiweiß- und RNS-Stoffwechsel in kurzem Intervall (bis 10 Minuten), während sie mittels ${ }^{3} \mathrm{H}$-Uridin, ${ }^{3}$ H-Cytidin und anderer radioisotopen Substanzen mit Dünndarm, Ileum, Colon und Leber beschäftigt haben. Die neuen Arbeiten von Amano, Leblond und NAdLer (1955), die bei verschiedenen Organen

den cytologischen Sitz der RNS-Synthese untersucht haben, beschäftigt sich nicht mit dem Problem über die Differenz zwischen der einkernigen Zelle und der zweikernigen. Die Untersuchung ïber die RNSSynthose mittels ${ }^{3} \mathrm{H}$-Uridin-Injektion in Bezug auf die Einflüsse der Fütterung und zugleich auf die Beobachtung für relativ längere Zeit nach der Injektion wurde also bisher noch von niemandem ausgef ührt.

Aus den oben erwähnten unseren Ergebnissen kann man sagen, ảaß die zweikernigen Zellen viel stärker als die einkernigen markiert werden. Dieses Resultat ist gültig nicht nur für die Drüsenorgane, sondern auch für die Darmepithelien. Diese Tatsache spricht eine Steigerung der synthetischen Fähigkeit der Ribonukleinsäure in den zweikernigen Zellen. Außerdem ist es zu bemerken, daß in den Drüsenorganen die Zahl der Silberkörner 28 Stunden nach der Injektion, also 3 Stunden nach der zweiten Fütterung, abnimmt, während in den Epithelzellen aus der Darmzotten dies nicht der Fall ist. So kann man sagen, daß sich in den Drüsenorganen die RNSSynthese je nach den Stunden (also je nach den Stunden nach der ersten Fütterung) steigert und dies sich bis zum Anfang der Refütterung fortsetzt.

Die Abnahme der Silberkörnerzahl nach der Refütterung (28 Stunden nach der Injektion, 3 Stunden nach der Refütterung) ist beträchtlich, so die Zahl der Silberkörner nach der Refütterung zeigt, im Vergleich mit der Zahl kurz vor der Refütterung, nur einhalben oder noch geringeren Wert. Diese Tatsache bedeutet, unserer Meinung nach, daß durch die gesteigerte RNS-Synthese produzierte und in der Drüsenzelle angesammelte RNS Substanz bei der Refütterung ausgeschieden wurde und nach der Refütterung eine neue RNS-Synthese stattgefunden hat. Die Zahl der Silberkörner in den Epithelzellen aus der Darmkrypten kann einige Stunden nach der Injektion (oder nach der ersten Fütterung) allmählich abnehmen, während sich in den Zellen aus der Darmzotten die Zahl der Silberkörner immer mehr vermehrt. Wir glauben, daß dies auf der Verschiebung der Epithelzellen von der Seite der Krypten her bis nach den Zotten beruht, da die Verschiebung der markierten Zellen der Krypten in die Zotten die 
Abnahme der Zahl der Silberkörner in den Krypten verursachen kann. Die Zunahme der markierten Zellen in den Zotten ist selbstverständlich.

\section{Zusammenfassung}

Um die RNS Synthese im Verdauungstraktus zu studieren, wurde ${ }^{3} \mathrm{H}$-Uridin in $15 \mathrm{~g}$ schwere Albinomäuse injiziert, und 2-28 Stunden nach der Injektion wurden die Zellen von Leber, Pankreas, Magen, Duodenum, Jejunum, Ileum und Colon in autoradiographischen Zell isolationsdauerpräparaten verfertigt. Die Tiere wurden 1 Stunde und 24 Stunden nach der Injektion gefüttert.

In den Zellen aus den Darmzotten vermehren sich die Silberkörner je nach den Stunden nach der Injektion, während sich in den Drüsenzellen die nach der Injektion zunehmenden Silberkörner durch die Refütterung (28 Stunden nach der Injektion) vermindern. Auch die Zahl der Silberkörner über die Zellen aus den Darmkrypten vermindert sich einige Stunden nach der Injektion. Diese Resultate zeigen, unserer Meinung nach, die RNS-Substanz, die nach der ersten Fütterung produziert und in der Drüsenzellen angesammelt wurde, durch die Refütterung verbraucht wurde. Die RNS-Synthese in den zweikernigen Zellen ist stets lebhafter als die einkernigen. Die Differenz der Zahl der Silberkörner über die Zellen aus den Zotten und den Krypten erzählt die Verschiebung der Zellen von Seiten der Krypten nach den Zotten.

\section{マウスの消化器官における RNA 合成のラジオオートグラフ的研究, ことに二核細胞について（内容自抄）}

消化器管における RNA 合成を研究するため体重 $15 \mathrm{~g}$ のマウスを 1 週間基礎食で飼い ならした後, ${ }^{3} \mathrm{H}$-uridine $20 \mu \mathrm{c} / \mathrm{g}$ 体重皮下注射し, 注射後 1 時間で給食して, 注射後 2 （㱓後 1)，4（3）８（7)，24（23），28（3）時間の 5 回にわたり 5 匹ずつ（ただし最後の群は

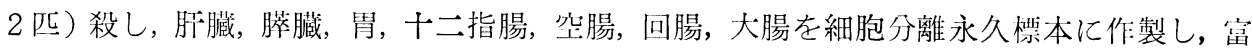
士 $\mathrm{EF}-2 \mathrm{E}$ 乳剂膜でおおって 55 日間露出, 型のごとく現像, 定着. HE 染色を施したラジ オオートグラフを作製した，各器官について ${ }^{3} \mathrm{H} \cdot$ Uridine の收り込みを各種細胞 10 箇ずつ の grain countingにより定量した結果は次の通りである.

肝細胞，膵細胞，胃の产細胞などの腺細胞においては全群共通に 2 核細胞の方が 1 核細 胞より銀粒千数が多い. 同一器官について時間的経過をみる之注射後 24 時間まで銀粘子 数は漸増し, 注射後28時間 (再給食後 3 洔間) で急減して再給食前の半分以下となる。乙 れは給食後 RNA 合成が盛んとなり再給食まで蓄積されるが再給食により総 RNA 量の半 分以上は消费されて新たに合成されると解される，小腸の上皮細胞においては腸絨毛の細 胞之晹陰盆の細胞とに分けて倠察すると, 十二指腸, 公腸, 回腸ともにすべての時期で陰

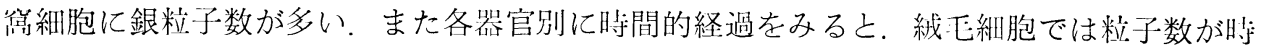
間とと屯に漸增するが，陰窩細胞では食後 7 2 3 時間が取大值を示し再給食後 3 時間で 減少し始める。大腸では杯細胞における銀粘子数が通常の円柱上皮細胞より常に多い.

これらのことから腸陰㸗の上皮細胞は ${ }^{3} \mathrm{H}$-Uridine 注射後合成したRNA をもったまま腺 細胞のごとく多量に消費することなく，小腸においては䋐毛へ移動すると解するととがで きる．また 2 核細胞の見られる腸䋐毛細胞において 2 核細胞之 1 核細胞の銀粒子数を比較

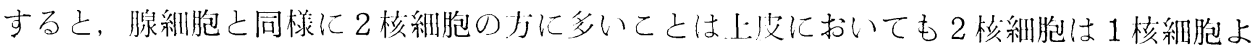


り RNA 合成の盛んなととを意味する.

\section{Literatur}

Amano, M., C. P. Leblond and N. J. Nadler : Radioautographic analysis of nuclear RNA in mouse cells revealing three pools with different turnover times. Exp. Cell Res. $38: 314-340$ (1965).

Linnartz-Niklas, A., K. Hempel nud W. Maurer: Autoradiographische Untersuchung über den Eiweiß- und RNS-Stoff wechsel tierischer Zellen während der Mitose. Z. Zellforsch. 62: 443-453 (1964).

Nagata, T.: A radioautographic study of the DNA synthesis in rat liver. Med. J. Shinshu Univ. $7: 17-25$ (1962).

Nagata, T., O. Shibata and Sh. Omochi : A new method for radioautographic observation on isolated cells. Histochemie 2 : 255-259 (1961).

Omochi, Sh., T. Nagata, O. Shibata and T. Nawa: Studies on the relationship between DNA synthesis and binucleate cells (Abstract, Japanese). Acta anat. nippon. $38: 18$ (1963).

Omochi, Sh., T. Nagata, K. Shimamura and M. Onozawa : Method of manufacturing the permanent preparations of isolated cells. Report IV (Japanese with English abstract). Acta anat. nippon. 33 : 20-23 (1958).

Omochi, Sh, T. Ojima and T. Inoue : A method of manufacturing the permanent preparation of isolated and detached epithelia (Japanese with Engl:sh abstract). Shinshu med. J. 1: 1-5 (1952). : An improved method of manufacturing the permanent preparation of isolated cells (Japanese with English abstract). Ibid. $4: 279-281$ (1955)

Omochi, Sh., T. Ojima and Y. Sunohara : Some improvement on the method of manufacturing the permanent preparation of isolated cells (Japanese with English abstract). Ibid. 5 : 232-234 (1956).

Schultze, B., W. Oehlert und W. Maurer : Über eine allgemeine Beziehung zwischen der Umsatzrate der Ribonukleinsäure und des Eiweißes in Organismus von Maus und Ratte. Biochim. biophys. Acta 49 : $33-46$ (1961). 